\title{
LAS IDEAS DEL ALUMNADO SOBRE EL CONCEPTO DE CÉLULA AL FINALIZAR LA EDUCACIÓN GENERAL BÁSICA
}

\author{
CABALLER, M. J. ${ }^{\mathrm{t}}$ y GIMÉNEZ, I. ${ }^{2}$ \\ ${ }^{1}$ CEP de Godella. \\ ${ }^{2}$ CEP de Valencia.
}

\section{SUMMARY}

This work presents research on children's ideas concerning cells. The concept of the cell is studied from 13 years onwards and is developed in many biology textbooks at this level. The autor's hypothesis is that the concept of the cell is very complex and that it is not possible to understand the functioning as a living organism, nor is it possible to understand the functioning of its organs until a basic knowlege of biochemistry, respiration and photosyntesis is acquired.

\section{INTRODUCCIÓN}

Una revisión bibliográfica de la última década sobre aspectos de la dicáctica de Ias Ciencias Naturales nos revela una gran preocupación por las ideas espontáneas de quienes aprenden (ver compilaciones de Teresa Serano y Pilar Jiménez 1987).

Estas ideas constituyen representaciones mentales que condicionan el aprendizaje de los conceptos. De acuerdo con Rosalyn Driver (1986) y otros autores (Osborne y Freiberg 1985) estas ideas intuitivas se comportan como verdaderos obstáculos que dificultan la adquisión de conocimientos.

Investigaciones realizadas con adultos, incluidas personas con formación universitaria, han mostrado que la cultura científica que se le supone a un individuo medio que ha cursado el bachillerato es sólo aparente: gran parte de los conocimientos que adquirió en el proceso educativo no han sido bien asimilados, o han sido olvidados, o de nuevo sustituidos por ideas tópicas y contradictorias con los conocimientos impartidos en la escuela (Bachelard 1971, Astolfi 1978, Giordan y Martinand 1988).

Por este motivo una de las líneas de investigación en el campo de la didáctica específica es la exploración y análisis de las representaciones mentales del alumnado y las dificultades para transformarlas o adecuarlas a las concepciones de la Ciencia (cambio conceptual según Posner et al 1982)
Nuestro trabajo (que forma parte de una investigación más amplia) se ha dirigido a la determinación de algunos aspectos de las ideas sobre el concepto de célula que pueda tener el alumnado al finalizar la Educación General Básica (13-14 años). Los antecedentes bibliográficos son escasos (Dreyfus y Jungwirth 1988, Brumby 1988), por lo que nos ha parecido un campo interesante de exploración.

\section{PLANTEAMIENTO DEL PROBLEMA}

Dado que gran parte del profesorado de nuestro país organiza el trabajo académico basándose en los libros de tex to y la propuesta que se deduce de ellos es el estudio de la organización interna celular, los procesos vitales de la célula y la relación de los procesos con los orgánulos celulares, es presumible que gran parte del alumnado de 13 y 14 años haya estudiado la célula y su organización bajo el supuesto de que estos conceptos pueden aprenderse significativamente a estas edades.

Nosotras pensamos que, si esta propuesta se lleva a cabo, Io más probable es que desemboque en un aprendizaje memorístico que se olvida rápidamente, porque el concepto de célula es muy abstracto, contruido a partir de numerosas investigaciones en microscopía electrónica y bioquímica. Pretender un nivel de conceptualización 
funcional y de correspondencia de morfología y función no parece muy sensato.

\section{HIPÓTESIS DE TRABAJO}

Creemos que, para los alumnos y alumnas de estas edades, la idea de célula llega a ser nebulosa y poco definida, la de un ser muy pequeño con algunas atribuciones parecidas a las de los seres vivos, es una idea adquirida superficialmente como instrumento para comprender la estructura (no el funcionamiento) de los seres complejos, pero sin entender realmente su funcionamiento, puesto que los procesos bioquímicos y los biofísicos que constituyen realmente los atributos del ser vivo no pueden ser descritos en términos de conocimientos cientificos a estas edades y mucho menos a nivel celular (Dreyfus y Jungwirth 1988).

\section{MÉTODO DE EXPLORACIÓN}

Basándonos en algunos artecedentes (Dreyfus y Jungwirth 1988), referencias al problema (Giordan y Martinand 1988 , Gagliardi 1987, Brumby 1982) y nuestra propia experiencia, procedimos a la elaboración de unos cuestionarios escritos que fueron propuestos a una población pequeña. Los resultados de cuestionarios se categorizaron y analizaron y con ello se elaboró uno nuevo que fue contestado por una muestra mucho más amplia de población, con la idea de que este nuevo cuestionario posibilitaría la obtención de respuestas más relevantes, categorizables y útiles. Fil cuestionario definitivo puede consultarse en el apéndice.

La exploración se desarrolló con 94 alumnos y alumnas de seis centros ( $8^{2}$ de EGB, 13-14 años).

\section{RESULTADOS Y SU ANÁLISIS}

\section{Respecto de una pregunta de respuesta abierta acerca del concepto de célula}

No contestan ............................................ $21 \%$

Constituyen los seres vivos ...........................51\%

Son elementos dotados de vida propia ..............36\%

(nacen, crecen, se reproducen)

Son la forma más sencilla de vida que existe .. $28 \%$

Forman tejidos y órganos y así constituyen

los seres vivos ....................................................2. $28 \%$

Forman parte del cuerpo humano .....................26\%

(sin aludir a otros seres vivos)

Teniendo en cuenta que la pregunta era abierta, esperábamos que contestara todo el alumnado y se diera una gran variabilidad de respuestas. Sin embargo llama la atención que un $21 \%$ del alumnado no contesta. Si no lo han hecho, parece razonable pensar que se debe a que no tienen una representación mental clara de aquello sobre lo que se les pregunta.
Por otra parte, el $28 \%$ del alumnado que propone la célula como la forma más sencilla de vida que existe es el mismo que la propone también como la constituyente de todos los seres vivos. Ello significa que de los 94 alumnos encuestados sólo el $28 \%$ tiene, aparentemente, una representación mental adecuada del concepto de célula.

Hay otro tipo de respuestas que por su baja incidencia no reseñamos, pero que muestran confusión entre el concepto de célula y molécula, célula y átomo, célula y tejido.

\section{Respecto de una pregunta abierta acerca de la forma celular}

Redondeada ................................................... 42\%

Alargada ....................................................... 10\%

Esférica ........................................................ 5\%

Varias formas especificadas y correctas ......... 13\%

Formas dependientes de la función ................... 3\%

(sin más aclaraciones)

Visión plana $26 \%$

(asemejándola a una rueda, disco, lenteja, huevo

frito, lupa, plato, hoja alargada, moneda, rec-

tángulo, suela de zapato, botón, plano...)

Visión tridimensional $52 \%$

(globo, pelota, huevo crudo con cáscara, gota

de agua, globo ocular, huevos de los peces...)

De los resultados de esta cuestión una de las cosas que más nos ha llamado la atención el que un $52 \%$ del alumnado atribuye tridimensionalidad a la célula, lo que pondría en entredicho la idea, generalmente aceptada entre el profesorado, de que los y las estudiantes tiene una representación plana de la misma.

Además constatamos que los ejemplos propuestos por el alumnado coinciden con los propuestos en los dibujos de los libros de texto.

\section{Respecto a una pregunta abierta sobre el contenido celular}

No contestan. $38 \%$

Mencionan la existencia de núcleo ....................36\%

Mencionan la existencia de citoplasma .............23\%

Mencionan la existencia de mitocrondrias .......12\%

Mencionan una «corteza externa» ................... 8'5\%

Mencionan la existencia de cloroplastos .............3\%

Mencionan la existencia de membrana ...............3\%

Explican que dentro de la célula hay algo, pero confunden nombres (vacuola, celulosa, nervios, glóbulos rojos, átomos, protones, neutrones, electrones, etc.)

Nos parece muy evidente la falta de alusiones a una estructura celular interna ( $38 \%$ no contesta y sólo el $36 \%$ recuerda que en el interior celular hay núcleo). Sin embargo cuando analizamos los libros de texto del ciclo 
el respiratorio o el digestivo de los seres humanos; evidentemente es imposible que existan esos aparatos en una célıla.

Se atribuyen a la célula funciones de organismos superiores en unos casos (por ejemplo sentir dolor o frío), pero no en otros.

Pensamos que estos datos concuerdan con las hipótesis de otros autores y autoras acerca de las características que definen las representaciones mentales del alumna-

\section{REFERENCIAS BIBLIOGRÁFICAS}

ASTOLFI, P.J.,1978. Les réprésentations des enfants en situation de classe, Revue Francaise de Pédagogie, Vol. 45, pp. 126-128.

BACHELARD, G., 1971. Epistemologie, textes choisis (PUF: París).

BRUMBY, M.N., 1982. Students perception of the concept of life, Science Education, Vol. 66 (4), pp. 613-622.

DREYFUS A. y JUNGWIRTH, E, 1988. The cell concept of 10 th graders: curricular expectations and reality, International Journal of Sciences Education, Vol. 10 (2), pp. 221-239.

DRIVER, R., 1986. Psicología cognoscitiva y esquemas conceptuales de los alumnos, Enseñanza de las Ciencias, Vol. 4 (1), pp. 3-15.

GAGLIARDI, R., 1987. Nous ne sommes pas des petits ballons. Les modèles spontanés des élèves de l'école italtenue sur la céllule. Actes IX Journées sur l'education Scientifique, Chamonix. do: inseguridad, elevado grado de contradicción, fuerte arraigamiento.

Conocer el interior celular sólo tendrá sentido cuando pueda hacerse intervenir la estructura en los procesos vitales de la célula. Mientras las funciones no pueđan ser bien comprendidas, será vano exigir el aprendizaje de estructuras y orgánulos celulares, aunque sea a nivel muy sencillo, pues quedará reducido a la memorización de las parejas «orgánulo-función», que en poco tiempo serán olvidadas o confundidas.
GIORDAN, A. y MARTINAND, J.L., 1988. Etât des recherches sur les conceptions des èléves en Biologie. (Ed. propia: París).

JMÉNEZ, M.P., 1987. Preconceptos y esquemas conceptuales en Biología. Selección bibliográfica, Enseñanza de las Ciencias, Vol. $5(2)$, pp. 165-167.

OSBORNE, P. y FREYBERG, 1985. Learning in Science. The implications of children's Science. Heinemann Publishers. Nueva Zelanda. Traducido al castellano. 1991. (Editorial Narcea: Madrid).

POSNER, G., STRIKE, K., HEWSON, P. y GERTZOG, W., 1982. Accommodation of a Scientific conception: toward theory of conceptual change, Science Education, Vol. 66 (2), pp. 221-227.

SERRANO, T., 1987. Representaciones de los alumnos en Biología: estado de la cuestión y problemas parasu investigación en el aula. Actas de las IV Jornadas de Investigación en la Escuela: Sevitla, pp. 157-161. 


\section{ANEXO \\ CUESTIONARIO DE EXPLORACIÓN}

¿Qué crees que es un célula?

¿Qué forma o aspecto crees que tienen las células? (puedes ayudarte poniendo un ejemplo).

¿Qué crees que hay en el interior de las células?

Marca con una $X$ aqueltas funciones que crees que putede realizar una célula:

Sentir calor

Sentir frío

Aprender a moverse

Sentir dolor

Expulsar residuos

Pensar

Descansar

Crecer sin límite

Crecer hasta un límite

Percibir sonidos

Absorber agua

Respirar

Desplazarse ante un estímulo

Moverse por prolongaciones del cuerpo

Marca con una $X$ aquelias funciones que crees que NO podría realizar una célula.

Sentir calor

Sentir frío

Aprender a moverse

Sentir dolor

Expulsar residuos

Pensar

Descansar

Crecer sin límite

Crecer hasta un límite

Percibir sonidos

Percibix luz

Absorber agua

Respirar

Desplazarse ante un estímulo

Moverse por prolongaciones del cuerpo 
Contesta si las siguientes afirmaciones son verdaderas ofalsas y explica por qué.

Las células respiran

Las células se alimentan

Las células se reproducen 